\title{
Stick-Slip Analysis of a Drill String Subjected to Deterministic Excitation and Stochastic Excitation
}

\author{
Hongyuan Qiu, Jianming Yang, and Stephen Butt \\ Faculty of Engineering and Applied Science, Memorial University of Newfoundland, St John's, NL, Canada A1B 3X5 \\ Correspondence should be addressed to Hongyuan Qiu; hq1622@mun.ca
}

Received 13 January 2016; Accepted 27 April 2016

Academic Editor: Evgeny Petrov

Copyright (C) 2016 Hongyuan Qiu et al. This is an open access article distributed under the Creative Commons Attribution License, which permits unrestricted use, distribution, and reproduction in any medium, provided the original work is properly cited.

Using a finite element model, this paper investigates the torsional vibration of a drill string under combined deterministic excitation and random excitation. The random excitation is caused by the random friction coefficients between the drill bit and the bottom of the hole and assumed as white noise. Simulation shows that the responses under random excitation become random too, and the probabilistic distribution of the responses at each discretized time instant is obtained. The two points, entering and leaving the stick stage, are examined with special attention. The results indicate that the two points become random under random excitation, and the distributions are not normal even when the excitation is assumed as Gaussian white noise.

\section{Introduction}

In oil and gas industry, wells are drilled for either exploration or production purposes. The drill string, a very long and slender structure, experiences various vibrations during drilling operations, which can have significant detrimental effects on the drilling system [1]. Those detrimental effects include decrease of rate of penetration (ROP), interference with measurement while drilling (MWD) tools, and causing fatigue of the drilling components. In general, three vibration modes exist in the drill string, namely, axial, torsional, and lateral. Among the three vibrations, torsional vibration has attracted significant research effort partially due to its severe negative effects on drilling efficiency and life of drill string components. In the open literature, the torsional vibration/dynamics of a drill string has been modeled in several ways [2-4]. A torsional pendulum with one or two degrees of freedom is often used [5-7] for modeling stickslip, one special type of torsional vibration. These models are good to look at the dynamics qualitatively; however, they may not be adequate to provide more quantitative insight into the problems under investigation. Thus, some other researchers modeled the system with the Finite Element Method (FEM) [8-10]. In modeling the torsional vibration, an important factor is the excitation to the system. Some researchers accounted for the friction between the drill string and the wellbore; others focused on the resistant torque on the bit $[1,2,5,6,11-13]$. Existing research has revealed that the excitation from the bit-rock interaction is especially complicated $[1,6,13]$, involving both friction and cutting mechanisms. Under certain conditions, the friction mechanism may cause stick-slip motion of the bit which has particularly negative effect on the drilling system. Some researchers examined the stick-slip motion and the complicated dynamics in torsion $[1,2,5,11-13]$. Undoubtedly, these research works are helpful to understand the complex dynamics of the drill string in rotation; however, limitations exist. First, both field test and theoretical analysis have indicated that the friction mechanism between two surfaces is very complicated; the friction coefficient, in reality, is related to various different factors, such as the profile of the surface, the materials, and the lubrication conditions. The value of friction coefficient is always highly scattered. Second, the downhole condition is highly unpredictable due to the many uncertain factors in the wellbore. These factors determine that the drill string vibration and dynamics cannot be well understood with deterministic theory; rather methods from random vibration and/or stochastic dynamics would be much more powerful tools. As a matter of fact, [14] realized this point already in as early as 1950s and proposed a probabilistic model. However, research work along this direction has progressed very little since then, probably due to the conceptual complexity of 
random vibration. Among the very few researchers working on random vibrations of drill string, [15] investigated lateral vibration with a nonlinear random model. In the work of Chevallier, the excitation for a tricone bit and the excitation for a PDC bit were modeled as a Kanai-Tajimi process and as band limited white noise, respectively. The nonlinearity was handled with a stochastic linearization technique. In recent years, [16-19] also investigated drill string dynamics with probabilistic models. The authors' focus was placed on the bitrock interaction and the drilling fluid effect on dynamics. In some other papers, $[20,21]$ also studied the uncertainties in the weight-on-hook.

In general, there is a lack of work on torsional vibration of drill strings from the random perspective. In view of this fact, this paper, which is based on the work of [22], focuses on the random torsional vibration of a drill string. FEM is used to build the dynamic model. The central difference method is then used to find the solution, and Monte Carlo (MC) simulation is carried out to obtain the statistics of the responses. The paper is organized as follows. In Section 2, a dynamic model is developed. Following that, the solution strategies used in both deterministic and random cases are presented in Section 3. Simulation results are presented and analyzed in Section 4. Finally, conclusions are drawn in Section 5.

\section{Formulation}

2.1. Dynamic Model. The drill string investigated in this paper is schematically shown in Figure 1. For convenience of mathematical derivation, it is assumed that the top is clamped, while the ground rotates with a constant speed. This does not change the nature of problem in terms of the relative motion. The drill string, including drill pipes and drill collars, is discretized into finite elements using linear Euler-Bernoulli beam theory. If only the rotation is considered, the element stiffness matrix $K_{e}$ and mass matrix $M_{e}$ are given by

$$
\begin{gathered}
K_{e}=\left[\begin{array}{cc}
\frac{G J}{l_{e}} & -\frac{G J}{l_{e}} \\
-\frac{G J}{l_{e}} & \frac{G J}{l_{e}}
\end{array}\right], \\
M_{e}=\left[\begin{array}{cc}
\frac{\rho J l_{e}}{3} & \frac{\rho J l_{e}}{6} \\
\frac{\rho J l_{e}}{6} & \frac{\rho J l_{e}}{3}
\end{array}\right],
\end{gathered}
$$

where $G$ is the shear modulus of the drill string material, $\rho$ is the drill string density, $J$ is the polar moment of inertia of drill string cross section, and $l_{e}$ is the element length.

By assembling the local stiffness and mass matrices, the global mass and stiffness matrices of the system can be obtained. After some mathematical manipulation, the governing equation of motion of the whole system can be represented by the following form:

$$
M \ddot{q}(t)+C \dot{q}(t)+K q(t)=T,
$$

where $q(t)$ denotes the global rotation displacement vector; $T$ represents the torque excitation to the system; $M, C$, and $K$

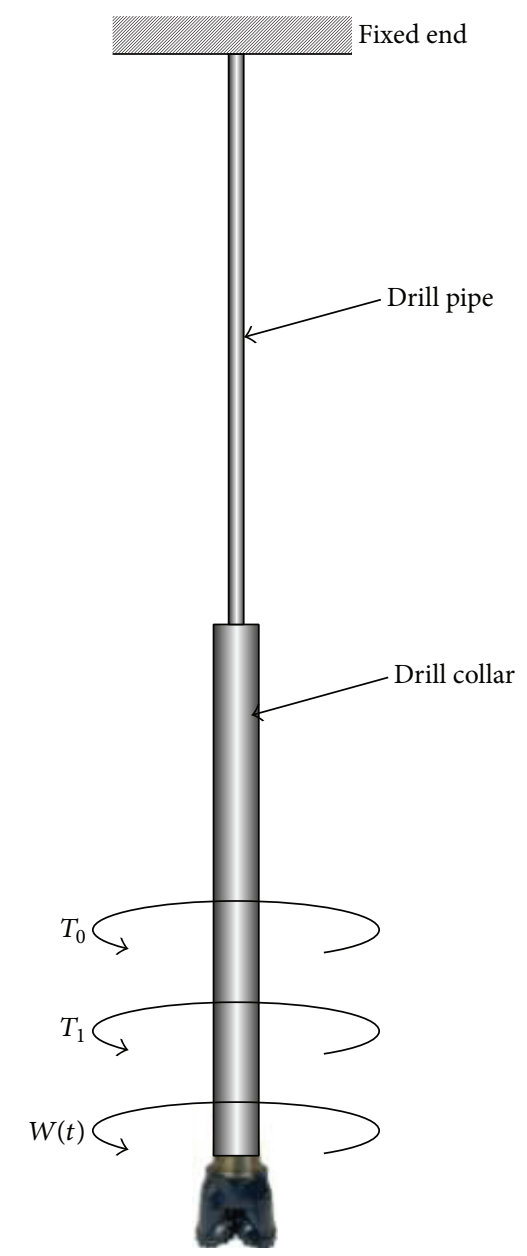

FIGURE 1: The dynamic model of the system.

are the system global mass, damping, and stiffness matrices, respectively; $C$ is assumed to be a linear combination of $K$ and $M$ as follows:

$$
C=\alpha M+\beta K,
$$

where $\alpha$ and $\beta$ are constants to be selected.

2.2. Excitation. In (2), the excitation to the system is generalized as torque $T$ which consists of several components explained below. The first important component of excitation is the periodic torque created by the cutting mechanism, denoted by $T_{0}$. It is straightforward to assume this excitation as a periodic function of time with a frequency of $N \omega$. For simplicity, it can be represented as a sinusoidal function as follows:

$$
T_{0}=a+b \sin (N \omega t)
$$

where $a$ and $b$ are constant parameters, $\omega$ is the rotary speed of the ground, and $N$ is the number of cutters on the bit.

Another important component of the excitation is torque $T_{1}$ created by the friction between the cutter and the bottom 


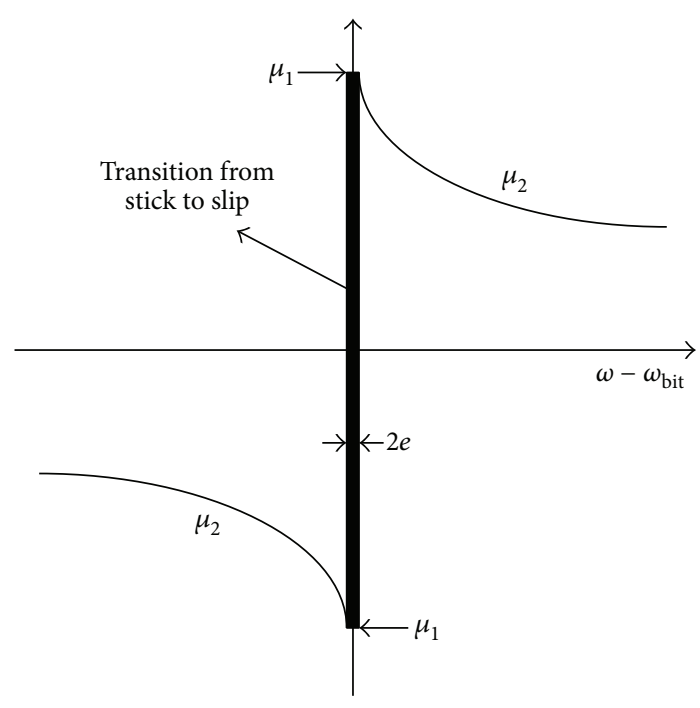

Figure 2: Torque created by the friction between the cutter and the bottom.

[2]. Depending on the two possible motion conditions, torque $T_{1}$ can be represented as

$$
T_{1} \begin{cases}\leq W r_{b} \mu_{1} & \left|\omega-\omega_{b}\right|=0 \\ =W r_{b} \mu_{2} & \left|\omega-\omega_{b}\right|>0\end{cases}
$$

where $W$ is the weight on bit, $\omega_{b}$ denotes the instantaneous rotary speed of the bit, $r_{b}$ is a number related to the radius of the cutter, and $\mu_{1}$ and $\mu_{2}$ represent the static and kinetic friction coefficients, respectively.

Given the fact that it is almost impossible to capture the exact $\omega-\omega_{b}=0$ in simulation, (5) can be recast into an alternative form as follows:

$$
T_{1} \begin{cases}\leq W r_{b} \mu_{1} & \left|\omega-\omega_{b}\right| \leq e \\ =W r_{b} \mu_{2} & \left|\omega-\omega_{b}\right|>e\end{cases}
$$

where $e$ is a preset small number, the proper value of which can be determined by trial and error in simulation.

There are several different expressions for $\mu_{1}$ and $\mu_{2}$ available in the literature $[2,5,12]$. The kinetic friction coefficient $\mu_{2}$ used in this paper is taken from Puebla and Alvarez-Ramirez [5] and is given as follows:

$$
\mu_{2}=\mu_{c b}+\left(\mu_{s b}-\mu_{c b}\right) \exp \left(-\gamma_{b}\left|\omega-\omega_{b}\right|\right) \text {, }
$$

where $\mu_{s b}$ and $\mu_{c b}$ are the static and Coulomb friction coefficients, respectively, $\gamma_{b}$ is a positive constant, and $\mu_{2}$ is substantially smaller than $\mu_{1}$. In general. The relationship between $\mu_{1}$ and $\mu_{2}$ in (7) is graphically shown in Figure 2.

Switching between static friction and dynamic friction is the primary cause for stick-slip. Numerous papers have investigated stick-slip of the drilling bit from the deterministic point of view $[2,5,11-13]$. However, the deterministic representation of the excitation above is highly idealized compared to the reality. The friction, in particular, is hard to model with deterministic theory. Experiments [23, 24] in both drilling industry and other areas have indicated that friction is stochastic or random in nature. According to Kilburn's work [23], friction force can be represented by combining a deterministic component and a Gaussian form random component. As such, to account for the effect of random component in the bit-rock friction, a Gaussian white noise $\xi(t)$ with a constant spectral intensity $S_{0}$ is added to the deterministic torque $T_{1}$ in this paper. Excitation $T$, therefore, is expressed as

$$
T=T_{0}+T_{1}+\xi(t) .
$$

\section{Solution Strategy}

3.1. Solution of Dynamic Model. The response of (2) to the excitation is numerically solved by using the central difference method. In this method, the time is first discretized into short time steps $\Delta t$; then the acceleration and velocity vectors at time $t_{i}$ can be written as [25]

$$
\begin{aligned}
& \dot{q}_{i}=\frac{1}{2 \Delta t}\left(q_{i+1}-q_{i-1}\right), \\
& \ddot{q}_{i}=\frac{1}{\Delta t^{2}}\left(q_{i+1}-2 q_{i}+q_{i-1}\right),
\end{aligned}
$$

where subscript $i$ indicates the time instant $t_{i}$. For the algorithm to be stable and convergent, the time step $\Delta t$ has to meet the following condition [26]:

$$
\Delta t<\Delta t_{\text {crit }}=\frac{2}{\omega_{n}},
$$

where $\Delta t$ and $\omega_{n}$ represent the time step and the maximum natural frequency of the system, respectively.

By substituting (9) into (2) and rearranging the terms, one has [25]

$$
q_{i+1}=\Delta t^{2} N_{1} T_{i}+N_{2} q_{i}+N_{3} q_{i-1}
$$

with

$$
\begin{aligned}
& N_{1}=\left[M+\frac{1}{2} \Delta t C\right]^{-1}, \\
& N_{2}=N_{1}\left[2 M-\Delta t^{2} K\right], \\
& N_{3}=N_{1}\left[\frac{1}{2} \Delta t C-M\right] .
\end{aligned}
$$

Equation (2) is highly nonlinear due to the presence of friction. For comparison purpose, it is solved for both deterministic and random cases. In the random case, the dynamic equation is solved to a certain time with randomly generated excitation samples, and the response statistics are obtained by Monte Carlo simulation.

The random excitation $\xi\left(t_{i}\right)$ in simulation is generated as follows [26]:

$$
\xi\left(t_{i}\right)=\sqrt{\frac{2 \pi S_{0}}{\Delta t}} U_{i}
$$

where $U_{i}$ are random number series generated by the computer which is normally distributed with zero mean and unit standard deviation. 
TABLE 1: Drill string parameters.

\begin{tabular}{lcc}
\hline Parameters & Drill pipe & Drill collar \\
\hline Length & $1,000 \mathrm{~m}$ & $200 \mathrm{~m}$ \\
Outer diameter & $0.127 \mathrm{~m}$ & $0.2286 \mathrm{~m}$ \\
Inner diameter & $0.095 \mathrm{~m}$ & $0.0762 \mathrm{~m}$ \\
Material density & $7850.0 \mathrm{~kg} / \mathrm{m}^{3}$ & $7850.0 \mathrm{~kg} / \mathrm{m}^{3}$ \\
Elastic modulus & $210 \times 10^{9} \mathrm{~N} / \mathrm{m}^{2}$ & $210 \times 10^{9} \mathrm{~N} / \mathrm{m}^{2}$ \\
Shear modulus & $7.6923 \times 10^{10} \mathrm{~N} / \mathrm{m}^{2}$ & $7.6923 \times 10^{10} \mathrm{~N} / \mathrm{m}^{2}$ \\
\hline
\end{tabular}

3.2. Strategy for Probability Density Estimate. In order to obtain the statistics of response, the ranges of the responses, both $q_{i}$ and $\dot{q}_{i}$, are divided into certain numbers of small intervals. Assuming the sample size of Monte Carlo simulation is $N_{1}$, the probabilistic density of the response falling into a specific small area in slip stage is computed by

$$
p_{1}=\frac{n_{1}}{N_{1} \delta_{q} \delta_{\dot{q}}} .
$$

In the stick case, the probabilistic density is calculated by

$$
p_{2}=\frac{n_{2}}{N_{1} \delta_{q}},
$$

where $\delta_{q}$ and $\delta_{\dot{q}}$ are the interval length along $q$ and $\dot{q}$ directions, respectively, $n_{1}$ and $n_{2}$ are the numbers of the solution falling into the slip area and the stick interval, respectively, and $p_{1}$ and $p_{2}$ are the $\mathrm{PDF}$ at the specific slip area and stick interval, respectively.

\section{Simulation Results}

The parameters of the drill string in the simulation are listed in Table 1. In the simulation, the drill string system is divided into 30 elements, 20 elements for the drill pipes and 10 elements for the drill collars. Some other parameters used in the simulation are listed in Table 2.

4.1. Results from Deterministic Case. It has been well known that stick-slip happens when the rotary speed is lower than a threshold value [27]. This phenomenon is also observed in the simulation of this paper. Under the simulation parameters given above and a rotation speed of $10 \mathrm{rad} / \mathrm{s}(95 \mathrm{rpm})$, the response of the deterministic part is shown in Figure 3. In this figure, the time history of the relative rotation speed between the bit and the rock is given in Figure 3(a). It can be clearly seen that the stick-slip motion exists. Two representative points, the leaving point and the entering point to the stick-slip, are marked in this figure. In the deterministic case, these points (time instants) within a motion period are uniquely determined. In Figure 3(b) the phase plane is shown; the stick-slip is characterized by the flat straight line. Increasing the rotary speed or decreasing the WOB can effectively mitigate the stick-slip [11]. However, decreasing the WOB should be done cautiously because it may have negative influences on drilling efficiency. A simulation with the same
TABLE 2: Other parameters used in simulation.

\begin{tabular}{lc}
\hline Parameter & Value \\
\hline$a$ & $2 \times 10^{4} \mathrm{Nm}$ \\
$W$ & $4 \times 10^{5} \mathrm{Nm}$ \\
$\mu_{1}$ & 0.3 \\
$S_{0}$ & 15 \\
$\beta$ & 0.03 \\
$N$ & 3 \\
$\mu_{s b}$ & 0.3 \\
$b$ & $5 \times 10^{3} \mathrm{Nm}$ \\
$r_{b}$ & $0.22 \mathrm{~m}$ \\
$e$ & $0.01 \mathrm{rad} / \mathrm{s}$ \\
$\alpha$ & 0.03 \\
$\Delta t$ & 0.0002 \\
$\mu_{c b}$ & 0.21 \\
\hline
\end{tabular}

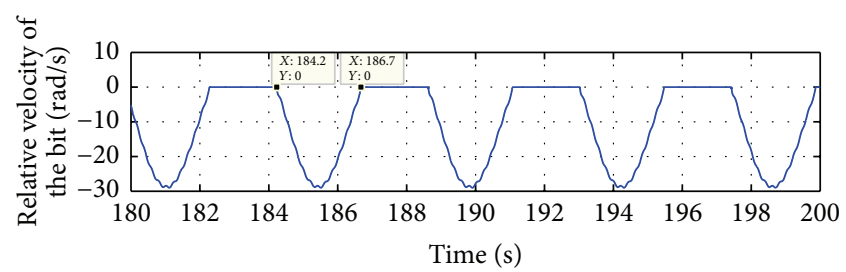

(a)

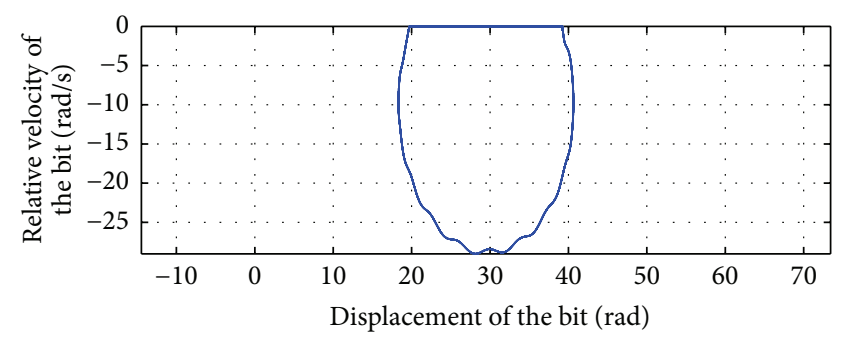

(b)

FIgURE 3: Stick-slip when the ground speed is $10 \mathrm{rad} / \mathrm{s}$ : (a) time history; (b) phase plane.

parameters but a higher rotation speed of $35 \mathrm{rad} / \mathrm{s}$ (332 rpm) is also conducted; the results are shown in Figure 4. Clearly, stick-slip is gone. The response is analogous to a sinusoidal curve, and no horizontal line exists in the phase plane any more.

4.2. Results from Random Case. Due to the random component of the friction, it is expected that the response will become random as well. Correspondingly, the phase plane will become diffused around a single line in the deterministic case. To capture the response features of the motion in the random case, $\mathrm{MC}$ simulation is conducted with a sample size of 200 and noise intensity of $S_{0}=15$.

Although field test data have long recognized the random nature of downhole vibration, no data have been reported on the strength of the randomness in public literature. The power 


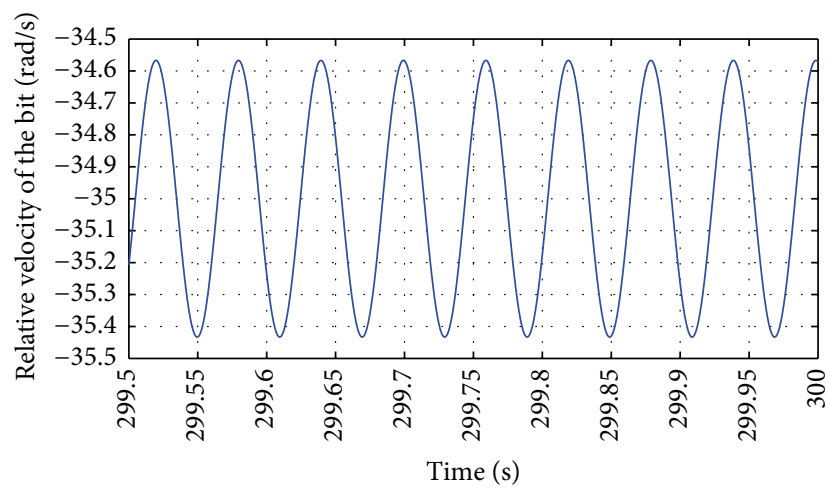

(a)

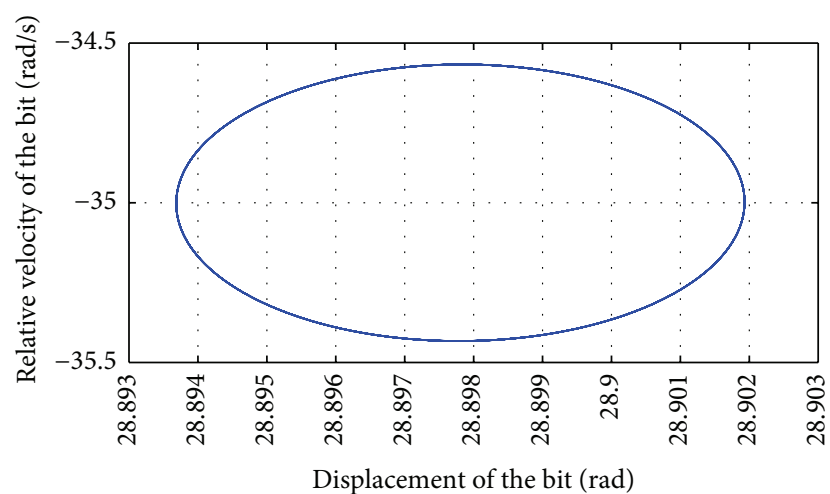

(b)

FIGURE 4: No stick-slip when the ground speed is $35 \mathrm{rad} / \mathrm{s}$ : (a) time history; (b) phase plane.

spectral density of $S_{0}=15$ may not be realistic in real drilling operation; however, this does not affect the significance of the study.

The first simulation case in random case is at the relatively high rotation speed of $35 \mathrm{rad} / \mathrm{s}$ which is the same as the deterministic case in Figure 4. Figure 5 gives the mean response of the case in which no stick-slip is observed. Compared with Figure 4, the two cases are very similar to each other. Here, for saving of space, we do not give the diffused phase plane for the random case.

The stick-slip case corresponding to the deterministic case in Figure 3, but with a random excitation component, is also simulated. The mean response of this case is shown in Figure 6. No obvious difference exists between this figure and Figure 3. However, if we draw all the simulation samples together in the phase plane, the single phase plane curve in Figure 3 will become diffused as shown in Figure 7. For any time instant, the points will be scattered in a range with varying probability. Using (14) and (15), the probabilistic distribution density at each time point can be obtained, as is shown in Figure 8. If stick-slip exists, the two representative points, entering and leaving the stick stage, have special interests, based on which some researchers developed control algorithms in order to mitigate the stick-slip. So knowing the times of these two points is crucial for the control strategy to be successful. In the deterministic case, the time

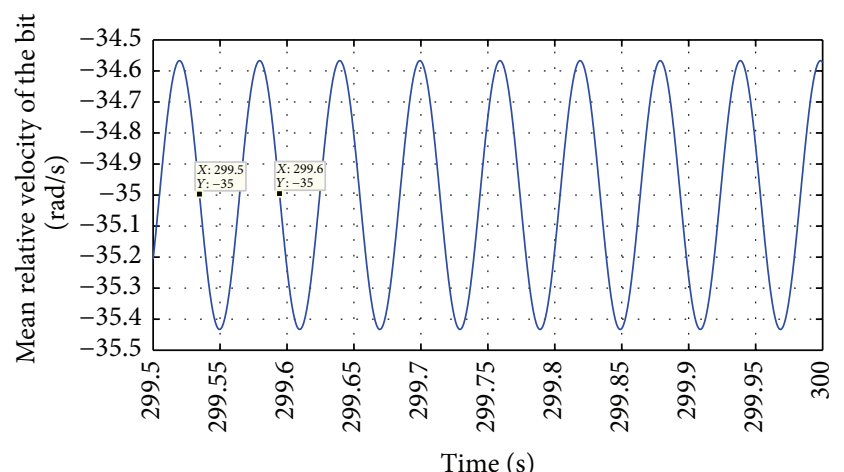

(a)

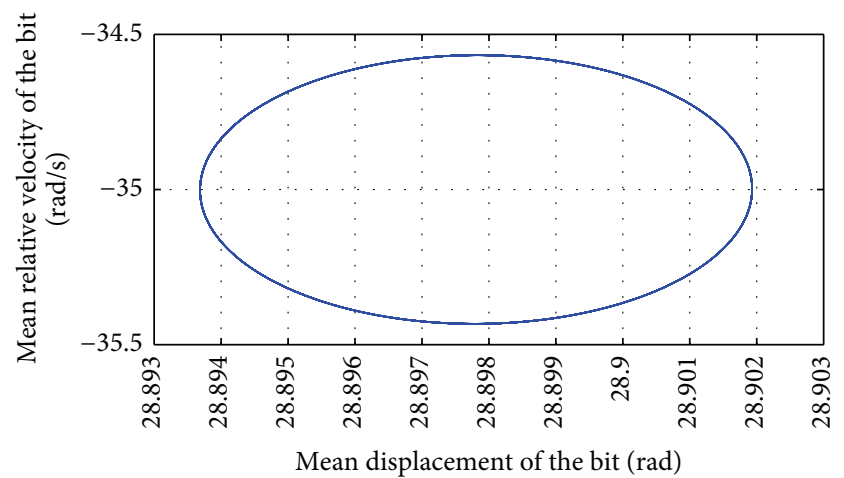

(b)

FIGURE 5: Mean response without stick-slip: (a) time history; (b) phase plane.

instants for these two points are deterministic. For instance, the two points in Figure 3 are $t=184.2 \mathrm{~s}$ and $t=186.7 \mathrm{~s}$, respectively. The statistics of these two points (marginal PDF) are shown in Figure 9. Clearly, both points are scattered in a range. In addition, the distribution is distorted from normal. The reason for that is the nonlinearity caused by the friction. In theory, for a nonlinear system, excitation with normal distribution may not lead to responses with normal distribution.

\section{Conclusions}

Using a finite element model, this paper investigates the stickslip behavior of a drill string subjected to both deterministic excitation and random excitation. Stick-slip behaviors in both deterministic and random cases are obtained through simulation and compared. The PDF of the stick-slip response in the phase plane is also obtained. The single curve of the phase plane in the deterministic case becomes diffused in a range. Correspondingly, the two points, entering and leaving the stick stage, become diffused too. Due to the nonlinearity caused by the friction, the PDF of these two points are not normal even when the excitation is assumed as Gaussian white noise. 


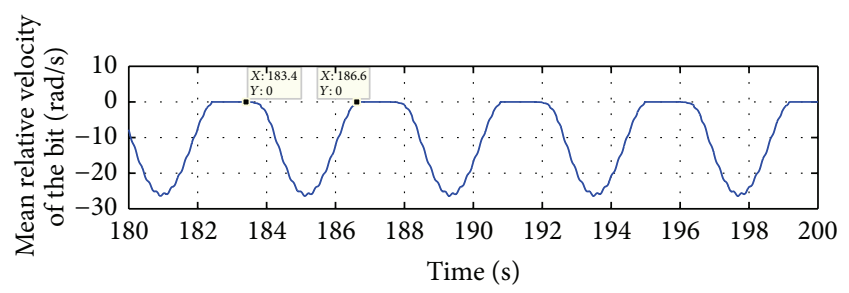

(a)

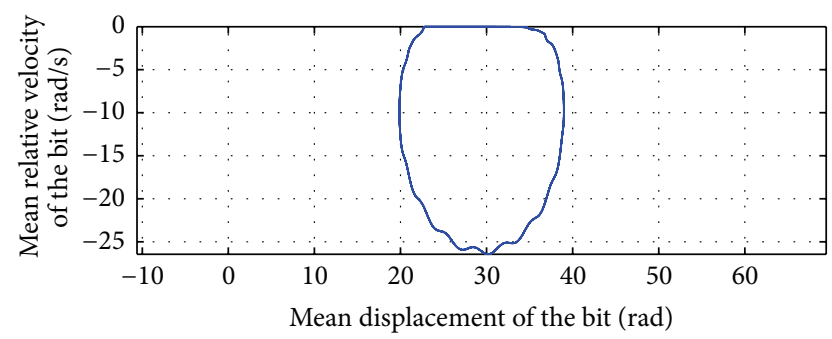

(b)

Figure 6: Mean response with stick-slip: (a) time history; (b) phase plane.

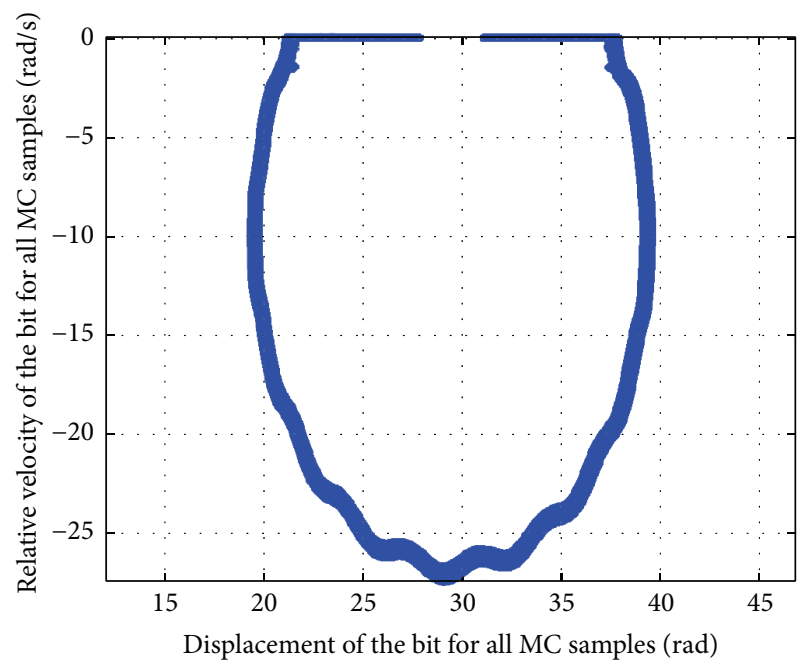

FIGURE 7: Phase plane for all MC samples between two representative points (stick-slip).

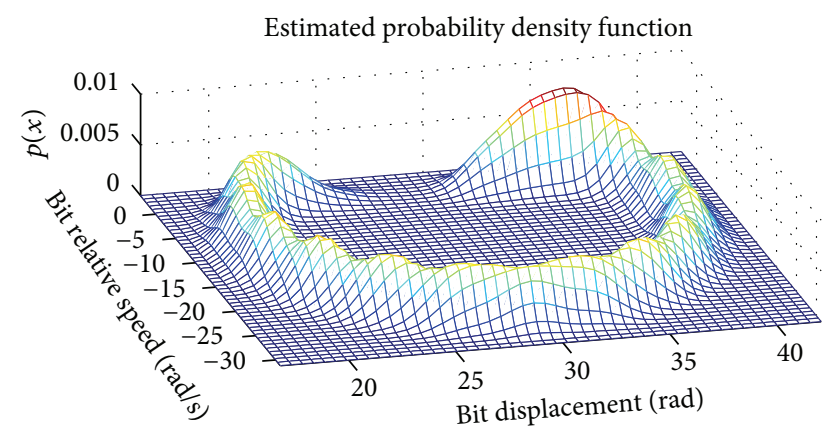

FIgURe 8: Probability density evolution in stick-slip.

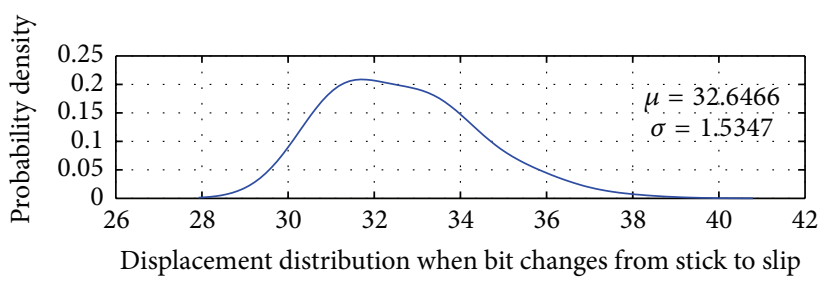

$-183.4 \mathrm{~s}$

(a)

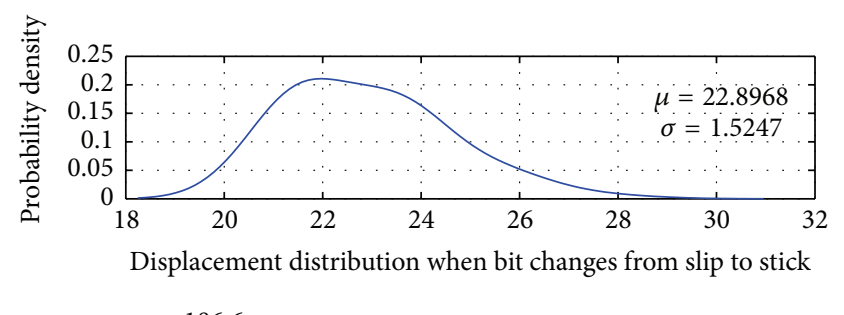

(b)

FIGURE 9: Probability density of the switching points: (a) leaving stick; (b) leaving slip.

\section{Competing Interests}

The authors declare that they have no competing interests.

\section{References}

[1] M. Zamanian, S. E. Khadem, and M. R. Ghazavi, "Stick-slip oscillations of drag bits by considering damping of drilling mud and active damping system," Journal of Petroleum Science and Engineering, vol. 59, no. 3-4, pp. 289-299, 2007.

[2] E. M. Navarro-López and D. Cortés, "Avoiding harmful oscillations in a drillstring through dynamical analysis," Journal of Sound and Vibration, vol. 307, no. 1-2, pp. 152-171, 2007.

[3] Y. A. Khulief, F. A. Al-Sulaiman, and S. Bashmal, "Vibration analysis of drillstrings with self-excited stick-slip oscillations," Journal of Sound and Vibration, vol. 299, no. 3, pp. 540-558, 2007.

[4] A. S. Yigit and A. P. Christoforou, "Coupled axial and transverse vibrations of oilwell drillstrings," Journal of Sound and Vibration, vol. 195, no. 4, pp. 617-627, 1996.

[5] H. Puebla and J. Alvarez-Ramirez, "Suppression of stick-slip in drillstrings: a control approach based on modeling error compensation," Journal of Sound and Vibration, vol. 310, no. 4-5, pp. 881-901, 2008.

[6] T. Richard, C. Germay, and E. Detournay, "Self-excited stick-slip oscillations of drill bits," Comptes Rendus-Mecanique, vol. 332, no. 8, pp. 619-626, 2004.

[7] C. Germay, N. Van de Wouw, H. Nijmeijer, and R. Sepulchre, "Nonlinear drillstring dynamics analysis," SIAM Journal on Applied Dynamical Systems, vol. 8, no. 2, pp. 527-553, 2009.

[8] M. A. Trindade, C. Wolter, and R. Sampaio, "Karhunen-Loève decomposition of coupled axial/bending vibrations of beams subject to impacts," Journal of Sound and Vibration, vol. 279, no. 3-5, pp. 1015-1036, 2005. 
[9] Y. A. Khulief and H. Al-Naser, "Finite element dynamic analysis of drillstrings," Finite Elements in Analysis and Design, vol. 41, no. 13, pp. 1270-1288, 2005.

[10] R. Sampaio, M. T. Piovan, and G. Venero Lozano, "Coupled axial/torsional vibrations of drill-strings by means of non-linear model," Mechanics Research Communications, vol. 34, no. 5-6, pp. 497-502, 2007.

[11] A. S. Yigit and A. P. Christoforou, "Stick-slip and bit-bounce interaction in oil-well drillstrings," Journal of Energy Resources Technology, vol. 128, no. 4, pp. 268-274, 2006.

[12] B. L. Van De Vrande, D. H. Van Campen, and A. De Kraker, "Approximate analysis of dry-friction-induced stick-slip vibrations by a smoothing procedure," Nonlinear Dynamics, vol. 19, no. 2, pp. 159-171, 1999.

[13] T. Richard, C. Germay, and E. Detournay, "A simplified model to explore the root cause of stick-slip vibrations in drilling systems with drag bits," Journal of Sound and Vibration, vol. 305, no. 3, pp. 432-456, 2007.

[14] J. L. Bogdanoff and J. E. Goldberg, "A new analytical approach to drill pipe breakage II," Journal of Engineering for Industry, vol. 83, no. 2, pp. 101-106, 1961.

[15] A. Chevallier, Nonlinear stochastic drilling vibrations [Ph.D. thesis], Rice University, Department of Mechanical Engineering, Houston, Tex, USA, 2001.

[16] T. Ritto, C. Soize, R. Sampaio et al., "Drill-string with uncertainty in the bit-rock interaction," in Proceedings of the 11th PanAmerican Congress of Applied Mechanics (PACAM '10), January 2010.

[17] T. G. Ritto, C. Soize, and R. Sampaio, "Non-linear dynamics of a drill-string with uncertain model of the bit-rock interaction," International Journal of Non-Linear Mechanics, vol. 44, no. 8, pp. 865-876, 2009.

[18] T. Ritto, C. Soize, and R. Sampaio, "Modeling uncertainties for local nonlinearities: application to the drill-string dynamics," in Proceedings of the Conference on Computational Methods in Structural Dynamics and Earthquake Engineering (COMPDYN '09), 2009.

[19] T. G. Ritto, C. Soize, and R. Sampaio, "Probabilistic model identification of the bit-rock interaction-model uncertainties in nonlinear dynamics of a drill-string," Mechanics Research Communications, vol. 37, no. 6, pp. 584-589, 2010.

[20] T. Ritto, C. Soize, and R. Sampaio, "Stochastic drill-string dynamics-random weight-on-hook (woh)," in Proceedings of the 13th International Symposium on Dynamic Problems of Mechanics (DINAME '09), 2009.

[21] T. G. Ritto, C. Soize, and R. Sampaio, "Stochastic dynamics of a drill-string with uncertain weight-on-hook," Journal of the Brazilian Society of Mechanical Sciences and Engineering, vol. 32, no. 3, pp. 250-258, 2010.

[22] H. Qiu, Dynamic analysis of a drill-string under deterministic and random excitations [M.S. thesis], Memorial University, Department of Mechanical Engineering, St. John's, Canada, 2014.

[23] R. F. Kilburn, "Friction viewed as a random process," Journal of Lubrication Technology, vol. 96, no. 2, pp. 291-299, 1974.

[24] N. Challamel, H. Sellami, E. Chenevez, and L. Gossuin, "A stick/slip analysis based on rock/bit interaction," Journal of Petroleum Technology, vol. 52, no. 12, pp. 30-31, 2000.

[25] C. W. S. To and M. L. Liu, "Large nonstationary random responses of shell structures with geometrical and material nonlinearities," Finite Elements in Analysis and Design, vol. 35, no. 1, pp. 59-77, 2000.
[26] C. Bucher, Computational Analysis of Randomness in Structural Mechanics: Structures and Infrastructures Book Series, vol. 3, CRC Press, 2009.

[27] M.-P. Dufeyte and H. Henneuse, "Detection and monitoring of the slip-stick motion: field experiments," in Proceedings of the SPE/IADC Drilling Conference, SPE-21945-MS, Society of Petroleum Engineers, Amsterdam, The Netherlands, March 1991. 


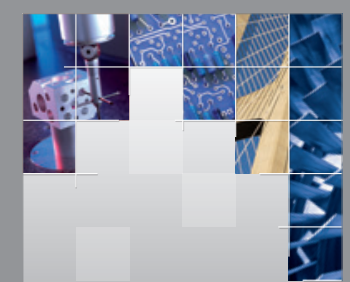

\section{Enfincering}
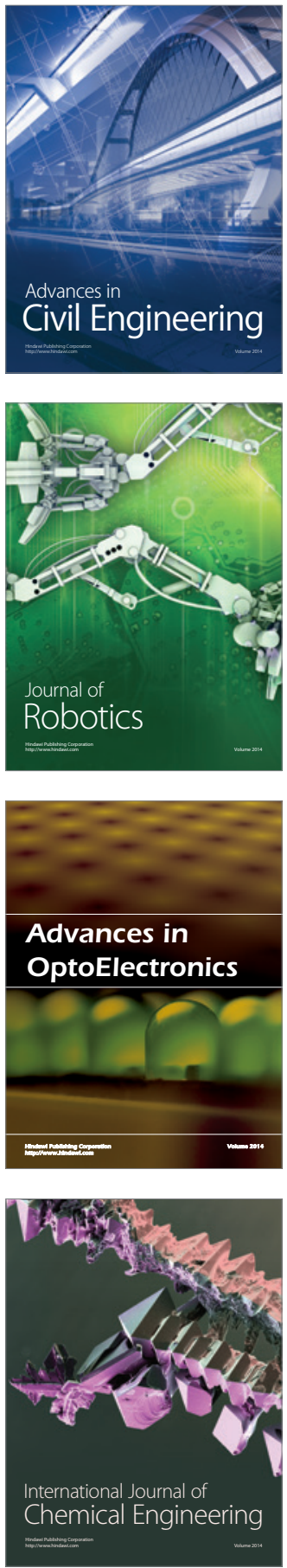

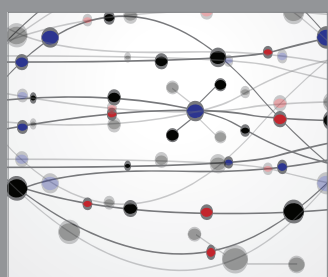

The Scientific World Journal

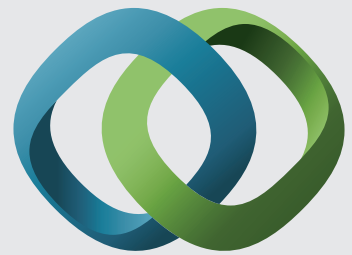

\section{Hindawi}

Submit your manuscripts at

http://www.hindawi.com
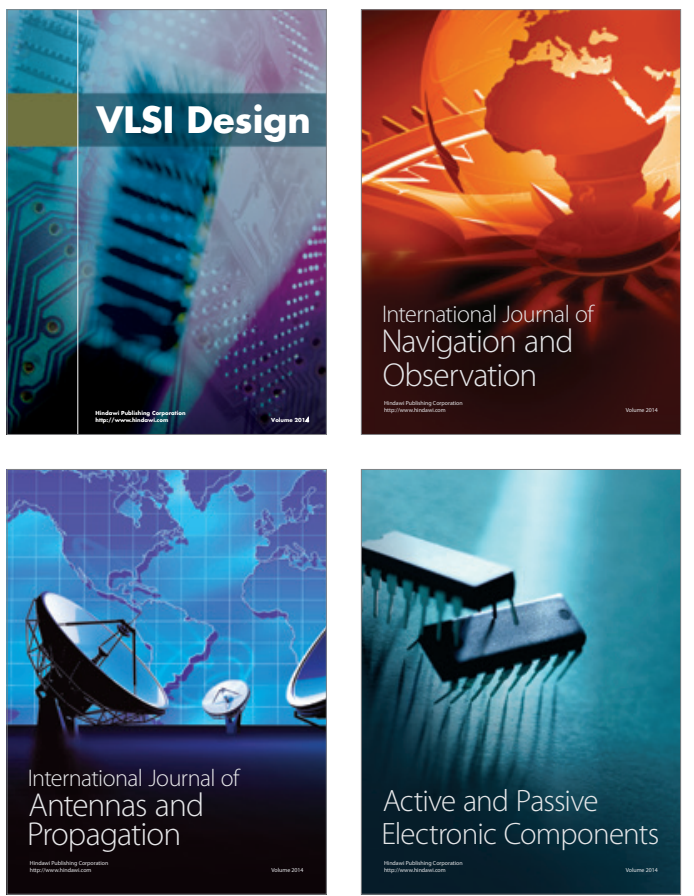
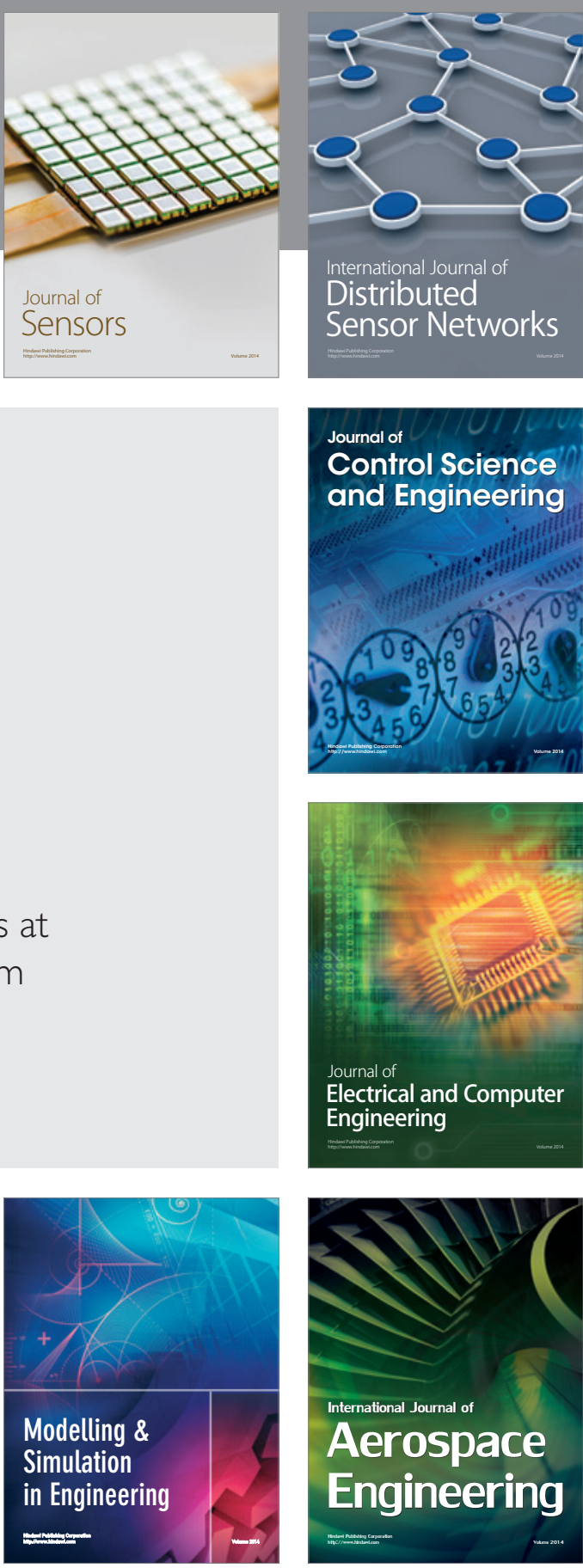

International Journal of

Distributed

Sensor Networks

Journal of

Control Science

and Engineering
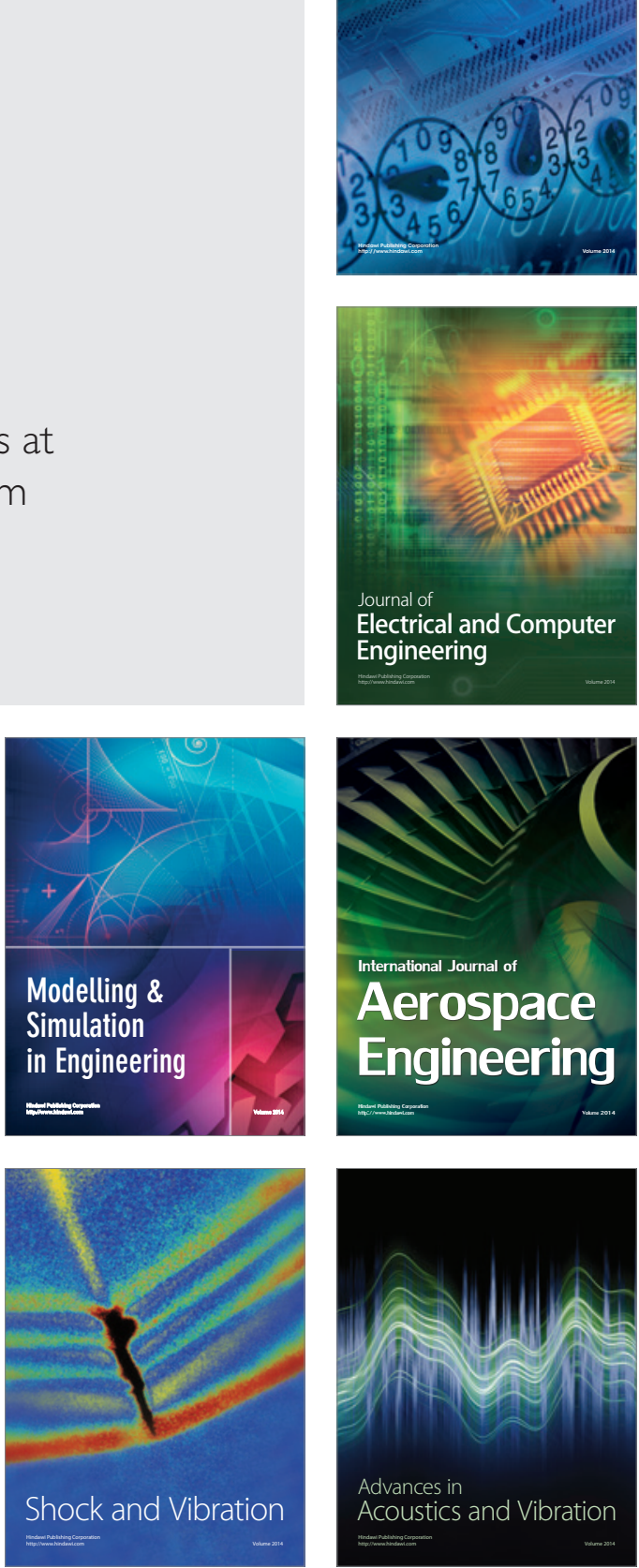